\title{
Familial spontaneous complete heart block in hypertrophic cardiomyopathy
}

\author{
ERIC K LOUIE, BARRY J MARON \\ From the Echocardiography Laboratory, Cardiology Branch, National Heart, Lung, and Blood Institute, \\ National Institutes of Health; and the F Edward Hebert School of Medicine, The Uniformed Services \\ University of the Health Sciences, Bethesda, Maryland, USA
}

SUMMARY Two siblings with hypertrophic cardiomyopathy developed spontaneous complete heart block requiring permanent pacemaker implantation at similar ages ( 29 and 33 years). The clinical, morphological, and haemodynamic expressions of hypertrophic cardiomyopathy differed considerably in these two patients. The sister had severe functional limitation due to dyspnoea, pronounced and diffuse left ventricular hypertrophy (maximum ventricular septal thickness of $41 \mathrm{~mm}$ ), and left ventricular outflow obstruction (peak subaortic gradient of $75 \mathrm{~mm} \mathrm{Hg}$ under basal conditions). In contrast the brother was symptom free, had only modest left ventricular hypertrophy which was confined to the anterior ventricular septum (maximal thickness of $16 \mathrm{~mm}$ ), and had no echocardiographic evidence of subaortic obstruction. These dissimilar findings in siblings with hypertrophic cardiomyopathy suggest that the predisposition to develop complete heart block was probably genetically transmitted, although it was unrelated to the phenotypic and clinical expression of the disease.

Hypertrophic cardiomyopathy is a primary myocardial disease, usually genetically transmitted as an autosomal dominant trait. ${ }^{1-3}$ This disease is characterised by great heterogeneity in the patterns of left ventricular hypertrophy ${ }^{4}$ that are present even among closely related patients. ${ }^{5}$ Complete heart block is rare in patients with hypertrophic cardiomyopathy, and its aetiology has not been defined. Sporadic examples, however, have been reported at all ages including those in a neonate in whom the abnormality was congenital ${ }^{6}$ and in several young adults. $^{7-12}$ Complete heart block that was apparently unrelated to acquired cardiac disease has also been reported in older adults ${ }^{13-16}$ and in elderly patients ${ }^{17-21}$ with hypertrophic cardiomyopathy.

Recently, we have evaluated a sister and brother with hypertrophic cardiomyopathy who both developed complete heart block as young adults. We believe that such an occurrence is particularly unusual and represents an opportunity to assess and discuss

Requests for reprints to Dr Barry J Maron, Cardiology Branch, National Heart, Lung, and Blood Institute, National Institutes of Health, Building 10, Room 7B-15, Bethesda, Maryland 20205, USA.

Accepted for publication 10 December 1985 the potential aetiology of complete heart block in this disease. Hence, the present report describes and compares the clinical and morphological features identified in a sister and brother with hypertrophic cardiomyopathy and complete heart block.

\section{Case reports}

Sister-The sister had experienced exertional dyspnoea and fatigue attributed to hypertrophic cardiomyopathy for seven years and also had a history of mild systemic hypertension $(165 / 100 \mathrm{~mm} \mathrm{Hg}$ while off medications and normal blood pressure on alpha methyldopa ( $1 \mathrm{~g}$ per day) and propranolol ( $30 \mathrm{mg}$ per day)). At initial evaluation at the National Institutes of Health, a grade $3 / 6$ systolic ejection murmur which increased during the Valsalva manoeuvre was present at rest; the electrocardiogram showed normal sinus rhythm ( 65 beats per minute) and left bundle branch block pattern. At cardiac catheterisation under basal conditions, pull-back recordings from the left ventricular apex to the ascending aorta showed systolic pressures of $240 \mathrm{~mm} \mathrm{Hg}$ in the distal left ventricular cavity and $165 \mathrm{~mm} \mathrm{Hg}$ in the outflow tract. A $75 \mathrm{~mm} \mathrm{Hg}$ peak to peak systolic pressure gradient was apparently localised to the 


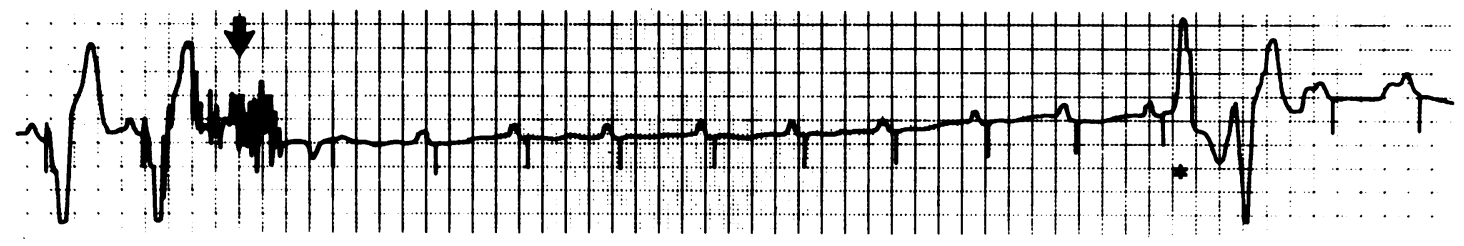

Fig. 1 Electrocardiogram confirming persistence of complete heart block (18 months after its onset) in the sister. At the left the tracing shows normal pacemaker function (atrial sensing and ventricular pacing with $100 \%$ capture). Subsequently (arrow) the pacemaker output was programmed to subthreshold levels; this resulted in pacemaker spikes which failed to capture the ventricles and unmasked $P$ waves which do not conduct to the ventricles. A seven second period of ventricular asystole ensued before the appearance of a ventricular escape beat (asterisk).

mid-ventricular cavity level distal to the tips of the mitral valve leaflets (and not associated with systolic anterior motion of the mitral valve on angiogram or $M$ mode echocardiogram); during the Valsalva manoeuvre the pressure gradient increased to $120 \mathrm{~mm} \mathrm{Hg}$. Left ventricular end diastolic pressure was $26 \mathrm{~mm} \mathrm{Hg}$.

Subsequently (at 33 years of age) the patient experienced a prolonged episode of lightheadedness and was found to have a heart rate of 20 beats per minute. Electrocardiogram showed complete heart block with sinus $P$ waves which failed to conduct to the ventricles and a slow idioventricular escape rhythm that was different from her previously identified left bundle branch block pattern. These electrocardiographic findings are consistent with an infranodal conduction block; however, in the absence of intracardiac $\mathrm{His}$ potential recordings a higher level of block cannot be excluded. Serum electrolyte, calcium, and creatine kinase concentrations were normal.

Permanent pacing was started with a Cordis $233 \mathrm{~F}$ pacemaker. At follow up one and a half years later the electrocardiogram showed ventricular pacing with $100 \%$ capture; complete heart block was confirmed by programming the output of the pacemaker to subthreshold levels. This uncovered the sinus $P$ waves that failed to conduct to the ventricles and resulted in a seven second period of ventricular asystole (Fig. 1).

Brother-The brother had not been evaluated for cardiovascular disease before the onset of complete heart block. He was symptom free until the age of 29 years when he fainted four times within a two week period. After the fourth episode of syncope he was found to have pronounced bradycardia ( 30 beats per minute). The electrocardiogram showed complete heart block. As in his sister's case an infranodal level of block was indicated by the failure of sinus $P$ waves to conduct to the ventricles and the presence of a slow idioventricular escape mechanism, though a more proximal level of block cannot be excluded. Serum electrolyte, calcium, and creatine kinase concentrations were normal.

Permanent pacing was started with an Intermedics 253-04 pacemaker. At follow up two and a half years later the electrocardiogram showed ventricular pacing with $100 \%$ capture; complete heart block was confirmed by programming the rate of the pacemaker to 30 beats per minute. This uncovered sinus $P$ waves which failed to conduct to the ventricles.

On physical examination a grade $1 / 6$ systolic ejection murmur was heard along the left sternal border which did not change appreciably with the Valsalva manoeuvre; blood pressure was $150 / 90 \mathrm{~mm} \mathrm{Hg}$. The

Table Echocardiographic findings in siblings with hypertrophic cardiomyopathy and complete heart block

\begin{tabular}{lrr}
\hline Variable & Sister & Brother \\
\hline Ventricular septal thickness (mm) & $41(8-12)^{\star}$ & $16(8-11)$ \\
Posterior free wall thickness (mm) & $8(8-11)$ & $9(8-11)$ \\
Septal to free wall ratio & $3.9(<1 \cdot 3)$ & $1 \cdot 8(<1 \cdot 3)$ \\
$\%$ Systolic thickening of septum & $0(>30 \%)$ & $25(>30 \%)$ \\
LV end diastolic dimension (mm) & $42(42-53)$ & $50(41-52)$ \\
LV end systolic dimension (mm) & $26(25-36)$ & $30(24-35)$ \\
\% Fractional shortening & $38(28-44 \%)$ & $40(28-44 \%)$ \\
RV end diastolic dimension (mm) & $18(9-26)$ & $21(9-26)$ \\
Left atrial dimension (mm) & $48(30-44)$ & $41(30-43)$ \\
\hline
\end{tabular}

Normal values or range are shown in parentheses. ${ }^{25-27}$

LV, left ventricle; RV, right ventricle. 

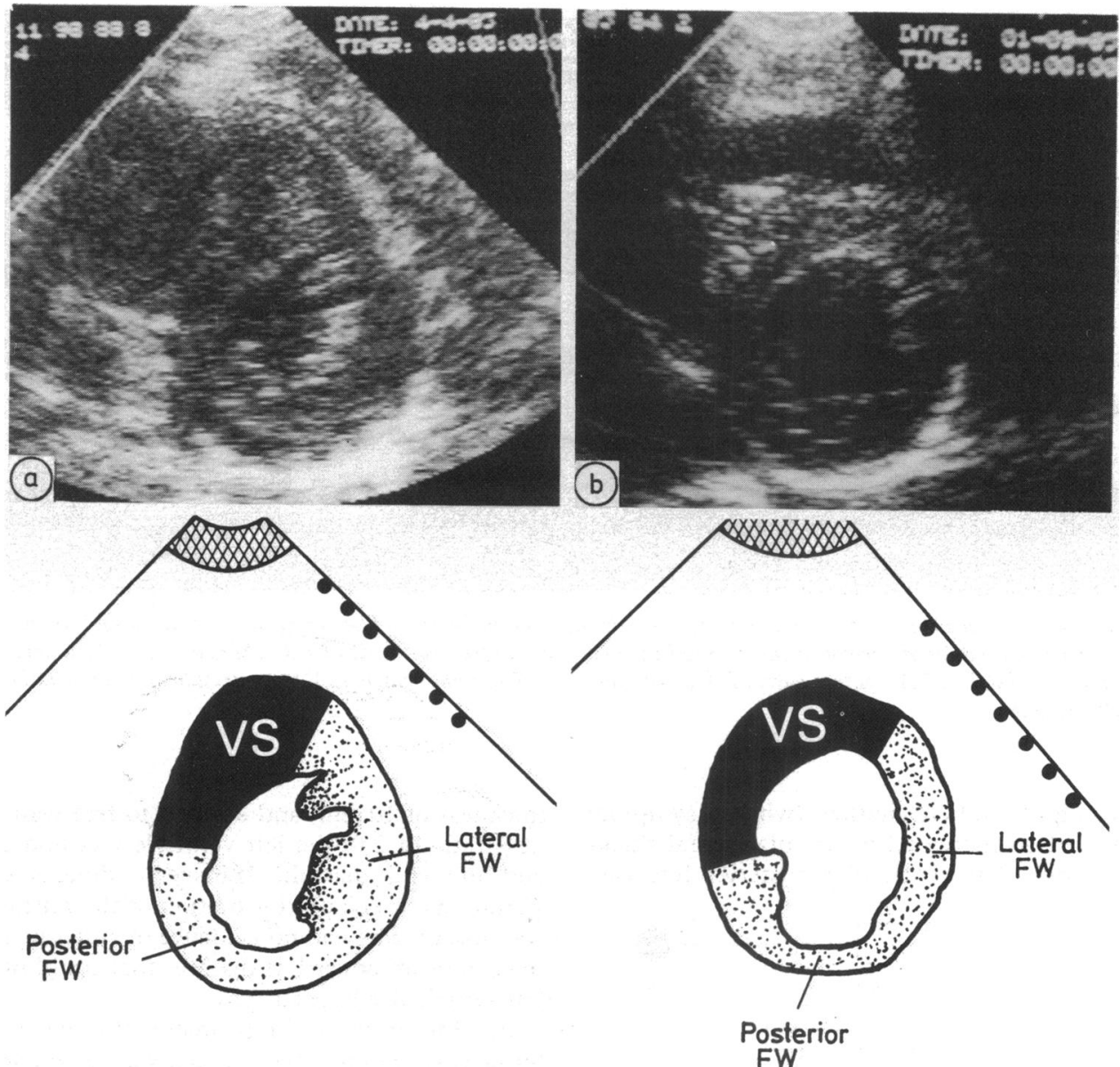

Fig. 2 Stop frames of short axis echocardiograms obtained during diastole showing contrasting morphological features in the sister and brother. Each echocardiogram is accompanied by a schematic illustration (below). (a) Pronounced ventricular septal thickening and substantial hypertrophy in the contiguous anterolateral free wall in the sister. (b) Mild anterior ventricular septal thickening in the brother; other areas of the left ventricular wall are of normal thickness. FW, free wall; VS, ventricular septum. Calibration dots are $10 \mathrm{~mm}$ apart.

absence of both an important heart murmur and of systolic anterior motion of the mitral valve on echocardiographic studies suggests the absence of a subaortic pressure gradient under basal conditions. The patient did not undergo cardiac catheterisation.

\section{Echocardiographic findings in siblings}

The $\mathbf{M}$ mode echocardiographic findings in the two siblings are compared in the Table. In each patient the left ventricle was not dilated and the pattern of left ventricular hypertrophy was asymmetric (ventricular septal to posterior free wall ratios were 3.9 in the sister and 1.8 in the brother). Cross sectional echocardiography showed the magnitude and distribution of hypertrophy to be markedly different in the siblings (Fig. 2). The sister had pronounced diffuse hypertrophy affecting the entire ventricular septum (maximum thickness of anterior septum $41 \mathrm{~mm}$ ) as well as the contiguous portion of the anterolateral left ventricular free wall (thickness of $22 \mathrm{~mm}$ ). In contrast the brother showed only mild wall thickening $(16 \mathrm{~mm})$ (Fig. 3) which was confined to the anterior ventricular septum; the posterior septum and the left ventricular free wall appeared normal in thickness. Neither patient demonstrated systolic anterior motion of the mitral valve (Fig. 3).

Echocardiographic analysis of other family members Genetic transmission of hypertrophic cardiomyopathy was demonstrated in relatives of the two 


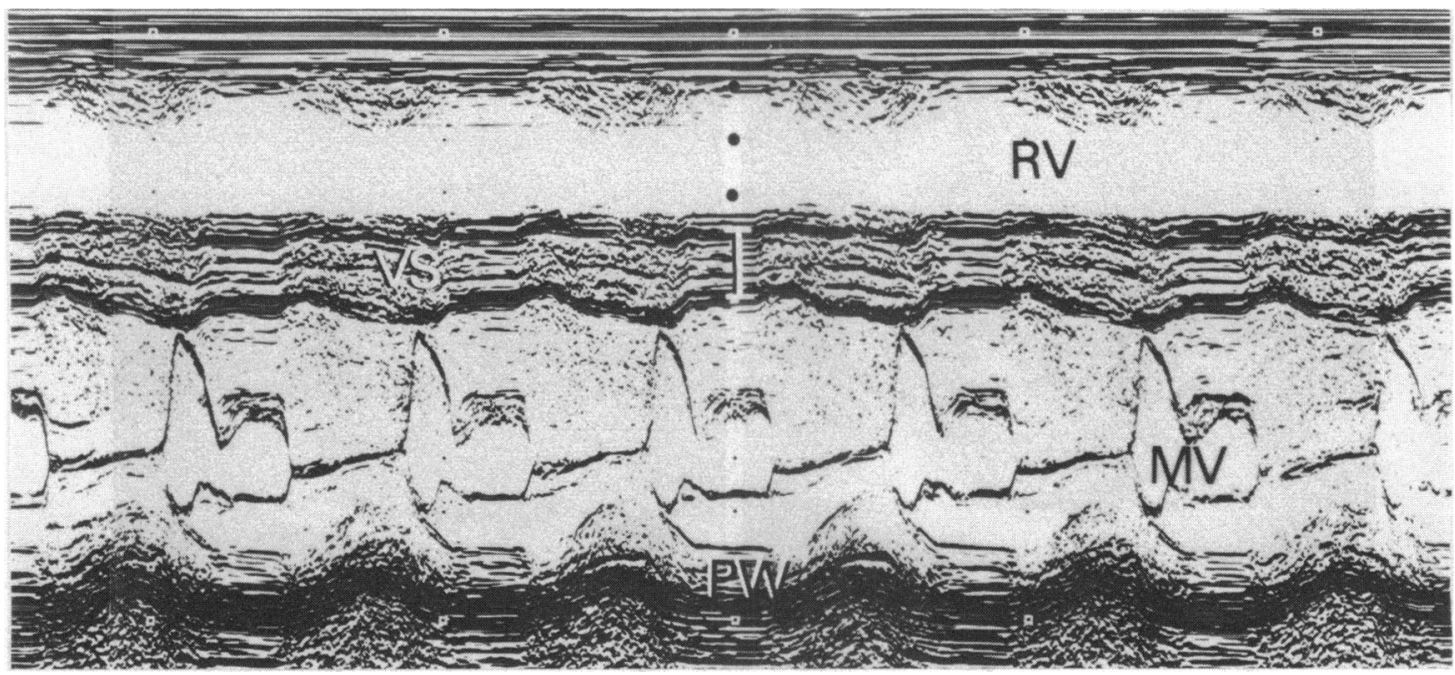

Fig. $3 M$ mode echocardiogram at the mitral valve level obtained in the brother. The ventricular septum is slightly thickened whereas the posterior wall is of normal thickness, resulting in a septal to free wall ratio of $1 \cdot 8$. There is no systolic anterior motion of the mitral valve. $M V$, mitral valve; $P W$, posterior wall; $R V$, right ventricle; $V S$, ventricular septum. Calibration dots are $10 \mathrm{~mm}$ apart.

siblings (Fig. 4). Their mother (who is symptom free) showed an increased ventricular septal thickness of $20 \mathrm{~mm}$, left ventricular posterior free wall

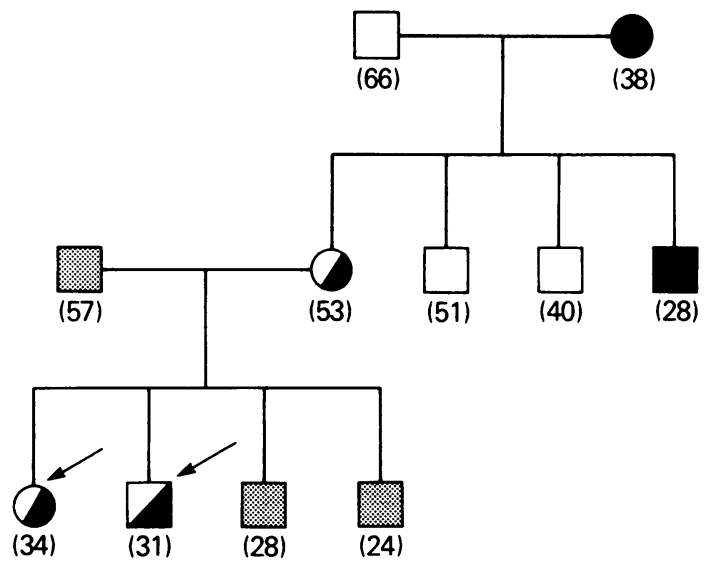

Fig. 4 Family pedigree for the two siblings (arrows) with hypertrophic cardiomyopathy and complete heart block.

Patient's ages (in years) at most recent follow up or at death are shown in parentheses. Solid symbols, sudden death presumed to be due to hypertrophic cardiomyopathy; half-filled symbols, alive with hypertrophic cardiomyopathy identified by echocardiography; stippled, alive with no evidence of hypertrophic cardiomyopathy on echocardiographic studies; clear symbols, individuals not studied with echocardiography; squares, males; circles, females. thickness of $10 \mathrm{~mm}$, and a septal to free wall thickness ratio of $2 \cdot 0$; the left ventricle was non-dilated and the end diastolic transverse dimension was $42 \mathrm{~mm}$. Systolic anterior motion of the mitral valve was absent. She had no evidence of systemic hypertension or other cardiac diseases that could produce left ventricular hypertrophy.

In addition the siblings' maternal uncle and maternal grandmother died suddenly at 28 and 38 years of age respectively. While we assume that these two relatives had hypertrophic cardiomyopathy, this diagnosis could not be confirmed in either individual because neither clinical evaluation during life nor necropsy examination of the heart were performed.

\section{Discussion}

This report describes the unusual occurrence of spontaneous complete heart block in two youthful siblings with hypertrophic cardiomyopathy. Onset of heart block was accompanied in each patient by syncope or lightheadedness and pronounced bradycardia necessitating the implantation of a permanent pacemaker. Neither patient had evidence of other cardiovascular abnormalities or metabolic alterations that could have been responsible for the development of complete heart block. While both siblings had a history of mild systemic hypertension, it is highly unlikely that this condition could have produced complete heart block in such youthful in- 
dividuals. Propranolol, which was taken by the sister, is not known to prolong the HV interval or produce infranodal heart block at usual therapeutic dosages. ${ }^{14}$ The mother of these two siblings with hypertrophic cardiomyopathy and complete heart block had no evidence of clinically overt connective tissue disease. ${ }^{22}$

The precise mechanism by which complete heart block occurred in our patients.has not been defined. Previous histopathological analyses of the conduction system in two patients with hypertrophic cardiomyopathy and advanced conduction system disease (one with HV prolongation and split His potentials and the other with complete heart block) identified alterations of potential pathophysiological importance, including interstitial fibrosis or myocardial necrosis and abnormal small intramural coronary arteries with thickened walls and luminal narrowing. ${ }^{1223}$

Whereas both our patients had hypertrophy affecting the basal septum in the region of the conduction system, the magnitude of septal thickening did not appear to be an important aetiological factor in producing complete heart block. The sister had pronounced and diffuse left ventricular hypertrophy with substantial ventricular septal thickening (in excess of $40 \mathrm{~mm}$ ); however, the brother showed only mild localised anterior septal thickening (of about $15 \mathrm{~mm}$ ). Indeed, these patients illustrate the heterogeneity and dissimilarity of patterns of left ventricular hypertrophy that are characteristic of first degree relatives with hypertrophic cardiomyopathy. ${ }^{5}$

Obstruction of the left ventricular outflow tract does not appear to be necessary for the spontaneous development of complete heart block in hypertrophic cardiomyopathy. The sister had a pronounced intraventricular pressure gradient at rest which appeared to be confined to the mid-cavity region of the left ventricle and was not associated with mitral systolic anterior motion, ${ }^{24}$ while the brother (who did not undergo cardiac catheterisation) had no echocardiographic evidence of basal subaortic obstruction.

The sister had had complete left bundle branch block pattern on electrocardiogram for at least six years before the occurrence of complete heart block. It is tempting to speculate ${ }^{16}$ that her left bundle branch block was indicative of pre-existing disease of the conduction system and was a forerunner of the subsequent complete heart block.

The dissimilar clinical, morphological, and haemodynamic expressions of hypertrophic cardiomyopathy in our two siblings suggest that the predisposition to develop complete heart block was genetically transmitted but was largely unrelated to the phenotypic and clinical expression of the disease.

\section{References}

1 Clark CE, Henry WL, Epstein SE. Familial prevalence and genetic transmission of idiopathic hypertrophic subaortic stenosis. N Engl f Med 1973; 289: 709-14.

2 ten Cate FJ, Hugenholtz PG, van Dorp WG, Roelandt J. Prevalence of diagnostic abnormalities in patients with genetically transmitted asymmetric septal hypertrophy. Am f Cardiol 1979; 43: 731-7.

3 Maron BJ, Nichols PF, Pickle LW, Wesley YE, Mulvihill JJ. Patterns of inheritance in hypertrophic cardiomyopathy: assessment by $M$-mode and twodimensional echocardiography. Am f Cardiol 1984; 53: 1087-94.

4 Maron BJ, Gottdiener JS, Epstein SE. Patterns and significance of distribution of left ventricular hypertrophy in hypertrophic cardiomyopathy. A wide angle, two-dimensional echocardiographic study of $125 \mathrm{pa}-$ tients. Am F Cardiol 1981; 48: 418-28.

5 Ciró E, Nichols PF, Maron BJ. Heterogeneous morphologic expression of genetically transmitted hypertrophic cardiomyopathy. Two-dimensional echocardiographic analysis. Circulation 1983; 67: 1227-33.

6 Maron BJ, Connor TM, Roberts WC. Hypertrophic cardiomyopathy and complete heart block in infancy. Am Heart f 1981; 101: 857-60.

7 Luisada AA. Subaortic muscular stenosis and complete heart block in an adolescent. Chicago Medical School Quarterly 1965; 25: 169-75.

8 Kariv I, Sherf L, Solomon M. Familial cardiomyopathy with special consideration of electrocardiographic and vectorcardiographic findings. $A m \mathcal{F}$ Cardiol 1964; 13: 734-49.

9 Gilgenkrantz JM, Cherrier F, Petitier H, Dodinot B, Houplon M, Legoux J. Cardiomyopathie obstructive du ventricule gauche avec bloc auriculo-ventriculaire complet. Arch Mal Coeur 1968; 61: 439-53.

10 Spilkin S, Mitha AS, Matisonn RE, Chesler E. Complete heart block in a case of idiopathic hypertrophic subaortic stenosis. Noninvasive correlates with the timing of atrial systole. Circulation 1977; 55: 418-22.

11 Sheikhzadeh A, Ghabussi P. A case of asymmetrical apical hypertrophy which is a form of hypertrophic nonobstructive cardiomyopathy with giant negative T-waves. Fpn Heart F 1982; 23: 843-9.

12 Gavrilescu S, Gavrilescu M, Streian C, Luca C. Hypertrophic obstructive cardiomyopathy associated with complete heart block. Pathologic correlations in a case studied with His bundle electrography. Acta Cardiol (Brux) 1974; 29: 241-9.

13 Chmielewski CA, Riley RS, Mahendran A, Most AS. Complete heart block as a cause of syncope in asymmetric septal hypertrophy. Am Heart $\mathcal{F}$ 1977; 93: 91-3.

14 Ingham RE, Mason JW, Rossen RM, Goodman DJ, Harrison DC. Electrophysiologic findings in patients with idiopathic hypertrophic subaortic stenosis. $A m \mathcal{F}$ Cardiol 1978; 41: 811-6.

15 Maron BJ, Merrill WH, Freier PA, Kent KM, Epstein SE, Morrow AG. Long-term clinical course and symptomatic status of patients after operation for hypertrophic subaortic stenosis. Circulation 1978; 57: 1205-13. 
16 Przybojewski JZ, Van Der Walt JJ, Ellis GC, Tiedt FAC. Hypertrophic cardiomyopathy complicated by complete heart block. Case report and review of the literature. S Afr Med ₹ 1984; 66: 847-55.

17 Tajik AJ, Giuliani ER, Frye RL, McGoon DC, Nunn SL. Muscular subaortic stenosis associated with complete heart block. Am F Cardiol 1973; 31: 101-4.

18 Matlof HJ, Zener JC, Harrison DC. Idiopathic hypertrophic subaortic stenosis and heart block. $\mathrm{Am} \mathcal{F} \mathrm{Car}$ diol 1973; 32: 719-22.

19 Johnson AD, Daily PO. Hypertrophic subaortic stenosis complicated by high degree heart block: successful treatment with an atrial synchronous ventricular pacemaker. Chest 1975; 67: 491-4.

20 Martinez R, Saponaro A, Barbato G, Martelli M, Scali D, Congelosi MM. Cardiomiopatia ipertrofica ostruttiva e blocco atrio-ventricolare. Considerazioni fisiopatologiche e terapeutiche. Boll Soc Ital Cardiol 1980; 25: 1365-72.

21 Touboul P, Kirkorian G, Atallah G, Cahen P, Zuloaga C, Moleur P. Atrioventricular block and pre-excitation in hypertrophic cardiomyopathy. Am $\mathcal{f}$ Cardiol 1984; 53: 961-3.

22 McCue CM, Mantakas ME, Tingelstad JB, Ruddy S. Congenital heart block in newborns of mothers with connective tissue disease. Circulation 1977; 56: 82-90.

23 Bharati S, McAnulty JH, Lev M, Rahimtoola SH. Idiopathic hypertrophic subaortic stenosis with split His bundle potentials. Electrophysiologic and pathologic correlations. Circulation 1980; 62: 1373-80.

24 Falicov RE, Resnekov L, Bharati S, Lev M. Midventricular obstruction: a variant of obstructive cardiomyopathy. Am $\mathcal{F}$ Cardiol 1976; 37: 432-7.

25 Henry WL, Gardin JM, Ware JH. Echocardiographic measurements in normal subjects from infancy to old age. Circulation 1980; 62: 1054-61.

26 Rossen RM, Goodman DJ, Ingham RE, Popp RL. Ventricular systolic septal thickening and excursion in idiopathic hypertrophic subaortic stenosis. $N \mathrm{Engl} \mathcal{F}$ Med 1974; 291: 1317-9.

27 Feigenbaum H. Echocardiography. 3rd ed. Philadelphia: Lea and Febiger, 1981: 550. 